\title{
Use and Modifications of Cervical and Upper Thoracic Laminar Screws in Posterior Stabilization
}

\author{
Burak EREN, Azmi TUFAN, Feyza KARAGOZ GUZEY, Ilker GULEC, Abdurrahim TAS, Ozgur AKTAS, \\ Mustafa VATANSEVER, Ebru DORUK, Murat YUCEL, Mustafa ORNEK
}

Health Sciences University, Bagcilar Training and Research Hospital, Neurosurgery Clinic, Istanbul, Turkey

\section{ABSTRACT}

AIM: To evaluate the results of patients who underwent axial, subaxial and upper thoracic laminar screw fixation for posterior stabilization.

MATERIAL and METHODS: The patients who underwent laminar screws at the cervical and upper thoracic levels in our clinic in a 5-year period were evaluated retrospectively.

RESULTS: A total of 54 laminar screws were used in 25 patients, aged between 6 and 82 years. The most frequent diagnoses were cervical spinal stenosis and craniovertebral junction anomalies. There were handicaps to perform other type of screws in 19 out of 25 screws during the first 4 years, and 9 out of 29 in the last year $(p=0.0009)$. Two modifications were performed in some cases. In 4 segments with thin lamina, a shorter screw was used to leave clear the thinnest part, and in 3 C2 levels with almost full-length bifid spinous process, shorter screws were inserted from the medial sides of the bifid processes with a more vertical orientation. There was ventral cortex penetration in 11 screws without new neurological deficits. One of them was removed because of its full thickness insertion into the spinal canal. The fusion rate was $75 \%$ in 16 patients who were radiologically followed for longer than 6 months. In one patient out of 4 without fusion, the unilateral screw was loosened, and in others the laminar screws were not loosened.

CONCLUSION: The laminar screw technique is easy, safe and effective at the C2, C7 and upper thoracic levels. Some modifications may be required due to the anatomical variations. It can be used at other subaxial levels, and also in selected cases where other techniques could not be performed.

KEYWORDS: Laminar screw, Posterior cervical stabilization, Posterior cervicothoracic stabilization, Screw malposition

\section{INTRODUCTION}

$\mathrm{V}$ arious posterior screw fixation methods have been described for axis such as transarticular, pedicle, pars and lateral mass screws; for subaxial cervical spine such as lateral mass and pedicle screws; and for upper thoracic spine such as pedicle screws. In 2004, Wright described a new screw technique for C2 stabilization as a translaminar screw, also called a laminar screw (34), as a salvage method in the patients with thin pedicles and small lateral masses. Thereafter, this technique was also used in $\mathrm{C} 7$ and upper thoracic spine as a salvage procedure at first $(11,17)$, especially in pediatric patients because of their small anatomy $(3,33)$. Usage of this technique increased as a first choice method in time because it is a simple technique and its risk of vascular and neural compromise is low.

We planned to evaluate retrospectively the results of our patients who underwent axial, subaxial and upper thoracic laminar screws for posterior stabilization. 


\section{- MATERIAL and METHODS}

We screened the screw methods used in our patients who underwent occipitocervical, upper cervical, cervical or cervicothoracic posterior stabilization during 5 years, between January 2012 and December 2016. In this time period, the posterior stabilization system, including at least one segment between $\mathrm{C} 2$ to T2, was performed in 67 cases for treatment of various disorders. In 25 out of 67 cases (congenital anomalies (24\%), degenerative diseases (32\%), trauma (28\%), infection $(8 \%)$, tumor $(4 \%)$, deformity $(4 \%))$, bilateral or unilateral laminar screws were placed into one or more segments between C2 to T2. Hospital inpatient and outpatient charts and radiological investigations present in the archive records of these 25 patients were evaluated retrospectively, and their demographic data, primary disorders, performed operations, perioperative complications, the length and diameter of the screws, and the last follow-up data were recorded.

The width and length of the lamina where the laminar screw was performed were measured on the preoperative axial sections of spinal computed tomography (CT) (Figure 1A, C), and height was measured on the midline sagittal reconstruction of CT (Figure 1B). The width of the lamina was measured as a width in its thinnest part, and the length was measured from the junction of the contralateral lamina and spinous process to the junction of the ipsilateral lamina and lateral mass (Figure $1 \mathrm{C})$. In addition, the laminar angle was measured between the line of length of lamina and vertical line (Figure 1D). For C2,
$\mathrm{C} 7$ and T1 levels, pedicle width, height and length were also measured (Figure 2A-C).

\section{Statistical Analyses}

Chi-square test or Fisher exact test was used to compare nominal variables according to their subject number. $F$ test and Student's t-tests were used for countable variables. A p value $<0.05$ was accepted as significant

\section{RESULTS}

\section{Demographic Data and Diagnoses}

There were 25 patients who underwent bilateral or unilateral laminar screws into at least one segment between $\mathrm{C} 2$ to T2. They were between 6 and 82 years old $(49 \pm 18$, mean \pm $\mathrm{SD})$, and the male/female ratio was $18 / 7$. The most frequent diagnoses were cervical spinal stenosis and craniovertebral junction and upper cervical anomalies. The diagnosis of the patients, stabilized segments and the levels that underwent laminar screws are shown in Table I.

\section{Screw Levels and Some Modifications of the Technique}

A total of 54 laminar screws (32 into C2, 1 into C5, 3 into C6, 16 into $C 7$ and 2 into T1) were used in 25 patients. Six of them were unilateral (2 C2 screws, 2 C7, one C5 and one C6), and the others bilateral. Screws were 3.5 or $4 \mathrm{~mm}$ in diameter, and 14 to $30 \mathrm{~mm}$ in length.
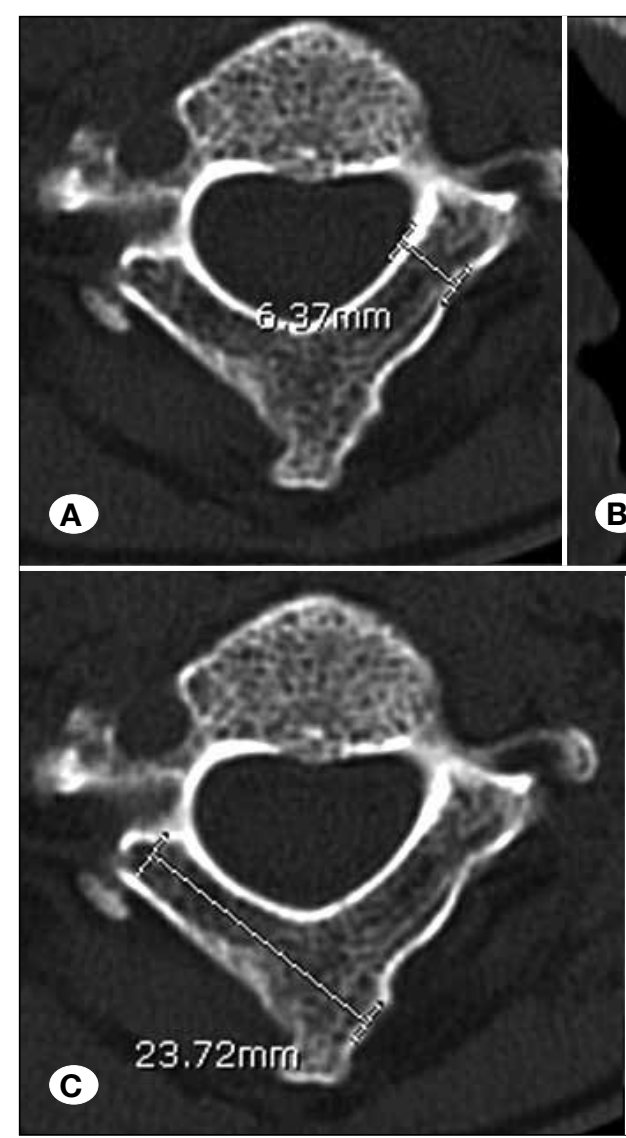
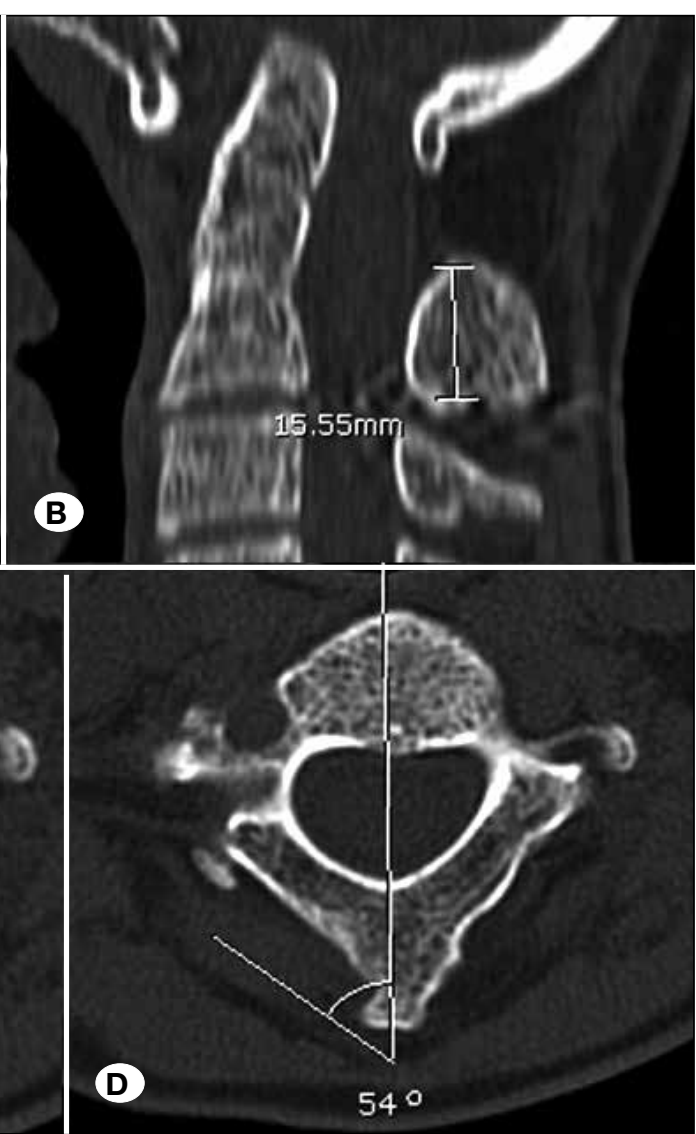

Figure 1: Methods of measurement of width (A), height (B), and length of lamina (C), and laminar angle (D) for laminar screw on axial section and midline sagittal reconstruction of $\mathrm{C} 2$ on CT. Note that laminar length is not true laminar length, but it is possible to use maximal laminar screw length for that level. 
The thickness, height and length of the laminas and pedicles of the segments where laminar screws were used are shown in Table II. In the 25 sites of C2 or C7 levels that laminar screws were used, pedicle thickness or height was not suitable to perform a pedicle screw procedure, or there was a high and/ or medial coursing vertebral artery (for C2). In the 4 C5 or C6 levels where laminar screws were used, lateral masses were too small (3) or were broken during surgery (1). In the 12 sites out of 32 for $\mathrm{C} 2,11$ sites out of 16 for $\mathrm{C} 7$, and 2 sites out of 2 for T1, laminar screws were used although there was no handicap to using a pedicle screw. The difference of rate of use of laminar screw without any pedicle anomaly was not statistically significant between the $C 2$ and $C 7$ levels $(p=0.41)$.

Laminar screws were placed unilaterally in 6 segments (3 C2, $3 \mathrm{C} 7$ ) because the other lamina was thinner than $4.5 \mathrm{~mm}$. A unilateral laminar screw was used in 3 of them and a pedicle or lateral mass screw was used at the other side, while the shorter screw was placed in 3 to leave clear the thinnest part that was located at the lateral part of the lamina (Figure 3). In a C6 segment, both laminae were thinner than $4.5 \mathrm{~mm}$, and

Table I: Diagnosis of the Patients, Stabilized Segments and Levels of Laminar Screws

\begin{tabular}{|c|c|c|c|}
\hline Diagnosis & n (\%) & Stabilization (n) & Levels of laminar screws (n) \\
\hline Congenital anomalies & $6(24)$ & $\begin{array}{l}\text { O-A (2) } \\
\text { O-SA (3) } \\
\text { O-C7 (1) }\end{array}$ & $\begin{array}{l}\text { C2 (9) } \\
\text { C5 (1) } \\
\text { C6 (2) } \\
\text { C7 (1) }\end{array}$ \\
\hline Degenerative diseases & $8(32)$ & $\begin{array}{c}\text { A-SA (6) } \\
\text { SA-C7 (2) }\end{array}$ & $\begin{array}{l}\text { C2 (11) } \\
\text { C7 (4) }\end{array}$ \\
\hline Trauma & $7(28)$ & $\begin{array}{l}\text { A-SA (1) } \\
\text { A-SA (2) } \\
\text { A-C7 (1) } \\
\text { SA-C7 (2) } \\
\text { SA-T1 (1) }\end{array}$ & $\begin{array}{l}\text { C2 (8) } \\
\text { C7 (7) } \\
\text { T1 (2) }\end{array}$ \\
\hline Infection & $2(8)$ & A-SA (2) & $\begin{array}{l}\text { C2 (2) } \\
\text { C6 (1) }\end{array}$ \\
\hline Tumor & $1(4)$ & SA-C7 (1) & C7 (2) \\
\hline Deformity & $1(4)$ & $\mathrm{A}-\mathrm{C} 7(1)$ & $\begin{array}{l}\text { C2 (2) } \\
\text { C7 (2) }\end{array}$ \\
\hline
\end{tabular}

O: Occipital, A: Axial, C: Cervical, SA: Subaxial, T: Thoracic.

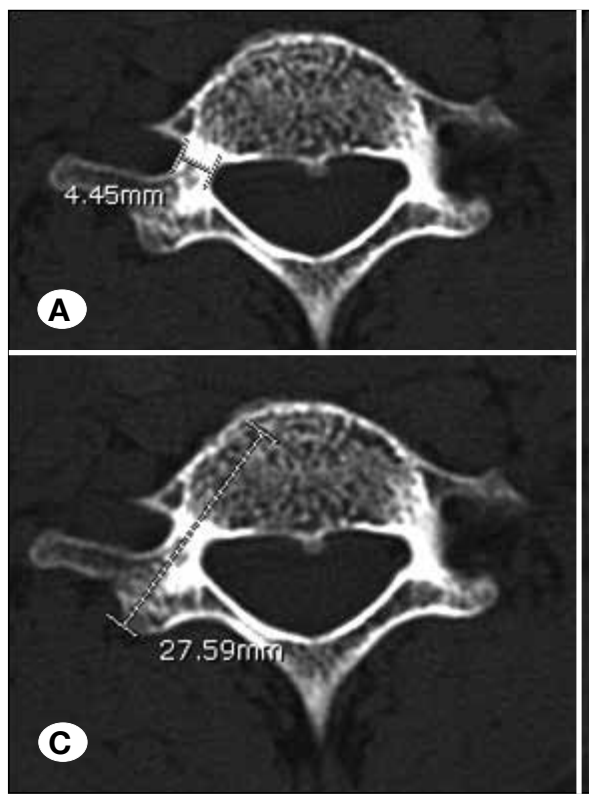

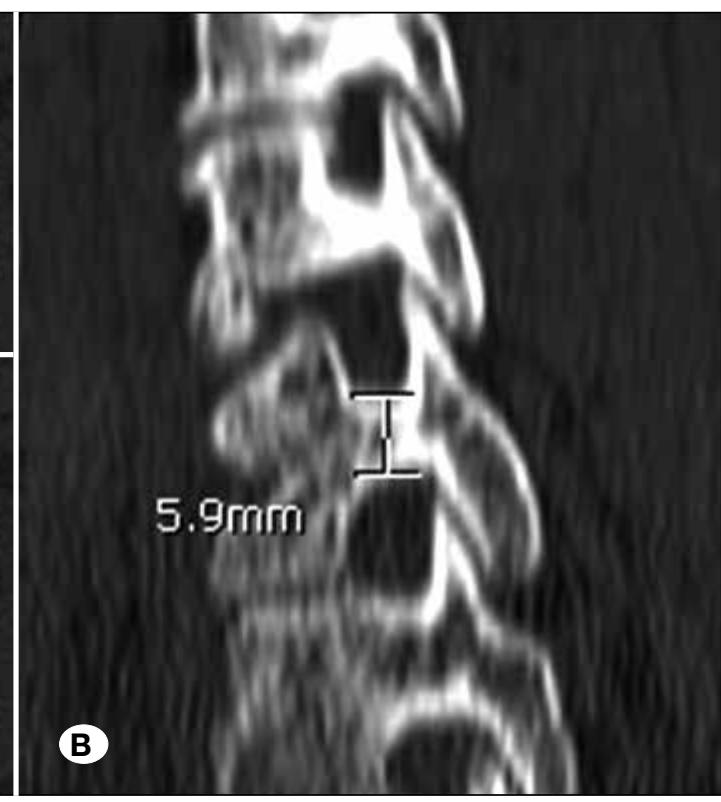

Figure 2: Methods of

measurement of width (A), height (B) and length of pedicle (C) for pedicle screw on axial section of C7 on CT scan. Note that pedicle length is not true pedicle length, but it is possible to use maximal pedicle screw length for that level. 
Table II: Measurements of the Laminae and Pedicles and the Levels of Laminar Screws that Were Used

\begin{tabular}{lccccccc}
\hline & \multicolumn{4}{c}{ Lamina } & \multicolumn{3}{c}{ Pedicle } \\
\cline { 2 - 8 } & Width $^{*}$ & Height $^{*}$ & Length & Angle & Width $^{*}$ & Height $^{*}$ & Length $^{*}$ \\
\hline $\mathbf{C 2}$ & $6.05 \pm 1.03$ & $11.68 \pm 2.51$ & $28.11 \pm 3.07$ & $47.65 \pm 8.19$ & $4.95 \pm 1.64$ & $7.17 \pm 2.21$ & $21.89 \pm 2.31$ \\
\hline $\mathbf{S A}$ & $5.1 \pm 0.59$ & $11.1 \pm 1.59$ & $19.52 \pm 1.66$ & $59 \pm 3$ & $3.15 \pm 0.37$ & $3.87 \pm 0.79$ & $21.65 \pm 1.66$ \\
\hline $\mathbf{C 7}$ & $5.73 \pm 1.05$ & $13.3 \pm 1.67$ & $25.36 \pm 3.92$ & $51.37 \pm 4.33$ & $5.09 \pm 1.06$ & $5.82 \pm 1.58$ & $27.06 \pm 2.55$ \\
\hline $\mathbf{T 1}^{\boldsymbol{}}$ & $6.2 / 7$ & $12.2 / 12.2$ & $34 / 30$ & $45 / 45$ & $6.6 / 8.1$ & $6.7 / 6.6$ & $33 / 32$ \\
\hline
\end{tabular}

C: Cervical, SA: Subaxial, T: Thoracic.

*Measurements are given as $\mathrm{mm}$ (average $\pm S D$ )

${ }^{\&} T 1$ measurements are shown as right and left measurements of same vertebra because only one patient underwent T1 laminar screws Length for laminae and pedicles was the maximal length of screw that could be used in that lamina or pedicle.

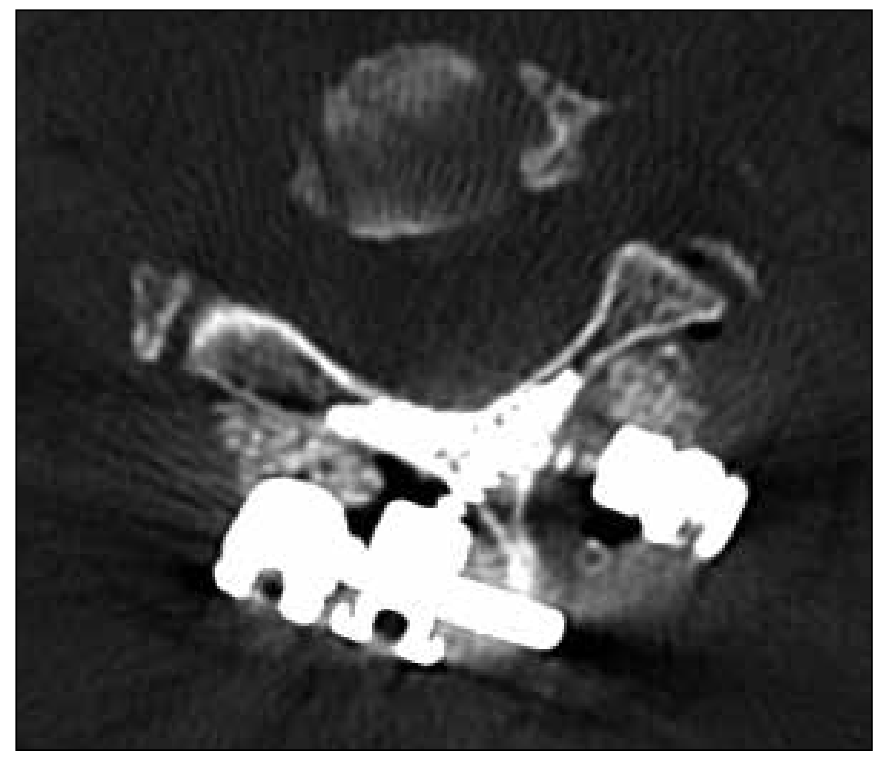

Figure 3: Postoperative axial CT scan. In a patient with thin left lamina, a shorter screw was used to leave clear the thinnest part of the lamina.

a unilateral short lateral mass screw was inserted into the lamina.

The laminar height in the midline was less than $9 \mathrm{~mm}$ and did not allow crossing the screws in the midline in 2 cases. In these 2 patients and in another one who underwent C2 laminar screws, insertion of bilateral screws was very difficult because the spinous process was bifid in almost its full length (Figure 4A). A modification of screw technique was performed with a more vertical orientation and shorter screws. In these cases, screws were inserted from the medial sides of the bifid spinous processes instead of the lateral sides by removal of the tip of the bifid spinous process (Figure 4B).

\section{Complications and Follow-up}

Only one screw was removed because of full thickness insertion into the spinal canal. This was a C2 screw, and there was no new neurological deficit due to this malposition. No new screw was inserted after its removal because of laminar fracture but posterior stabilization system loosening developed 8 months later and revision was required. In the other 10 screws (C2: 4, C7: 6), there was minimal bone cortex penetration $(<2$ $\mathrm{mm}$ ) through the spinal canal. None of them caused any complication, and none was removed. The malposition risk (consisting of minimal bone cortex penetration also) was not significantly different between $C 2$ and $C 7$ screws $(p=0.089)$. None of the variables (laminar thickness, height, length, or angle) was statistically different between the levels with or without malpositioned screws.

One patient who was tetraplegic due to cervical spinal cord injury died 6 days after the operation. One patient died 2 months after the operation due to pneumonia. He had tetraparesis with 1-2/5 motor strength due to spinal traumabased cervical spinal stenosis but his tetraparesis had improved and he could mobilize with a walker one month after the operation. The other 23 patients were followed for 2 to 49 months $(12.3 \pm 10.9$ months, mean $\pm S D)$. In a patient where C3 to $\mathrm{C} 7$ posterior stabilization was performed after posterior decompression of the spinal canal for cervical spinal stenosis, C3 and C4 lateral mass screws loosened after 15 months but the $\mathrm{C} 7$ laminar screws did not loosen. In 2 patients with craniovertebral junction anomalies, fusion did not develop and a second operation was necessary 14 and 20 months after the operations, respectively. With the patient whose one C2 laminar screw was removed because of malposition, there were a total of 4 patients in whom fusion did not develop. In the other 2 patients who had been operated 12 and 8 months previously respectively, there were no follow-up radiologic investigations except early postoperative control CTs because they lived in other cities. However, they declared during the phone interview that they had no complaint. Follow-up of other patients was uneventful. There were 16 patients who were followed radiologically longer than 6 months and in 12 of them, except the 4 mentioned above, fusion had developed at their last follow-up (75\%). In 3 of the 4 patients without fusion, laminar screws did not get loose. The C2 laminar screw was loosened in only one patient with unilateral C2 screw due to the removal of the other one because of misplacement. In 5 cases, the follow-up period was shorter than 6 months and fusion had not developed yet. 

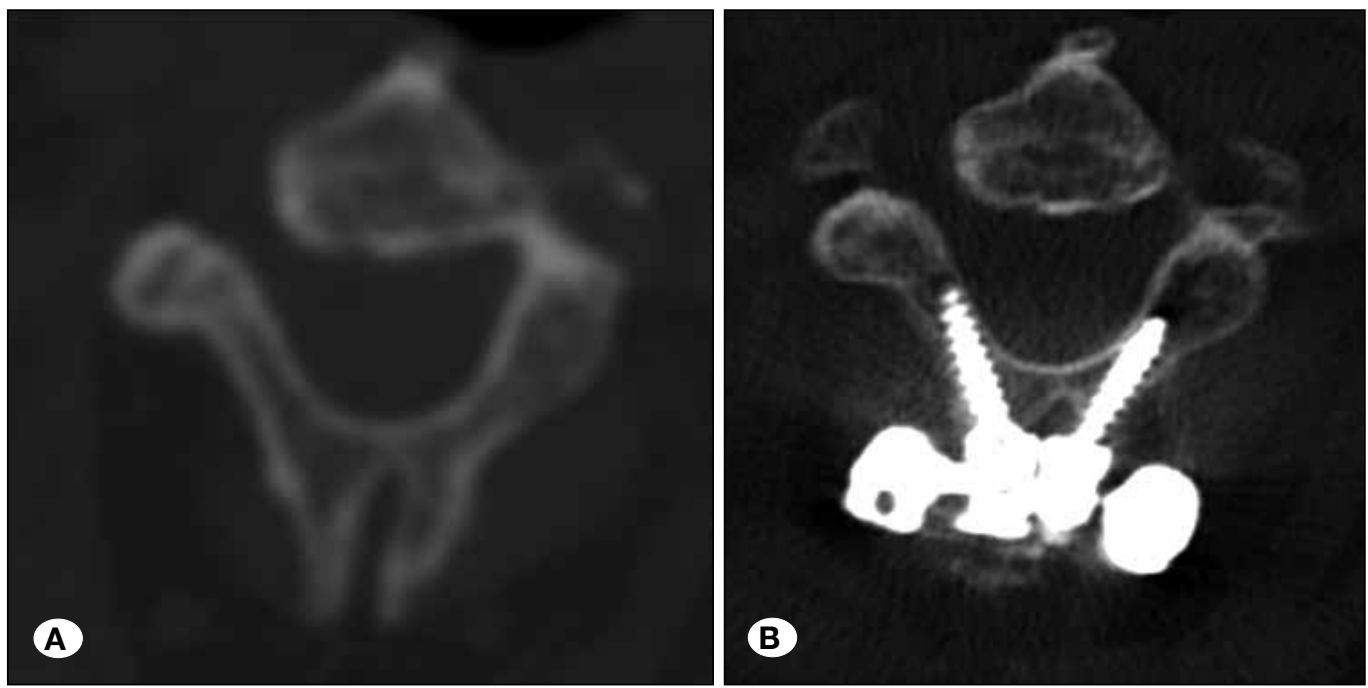

Figure 4: Almost full-length bifid $\mathrm{C} 2$ spinous process (A) and modification of laminar screw technique with more vertical and shorter screws performed from the medial side of process (B).

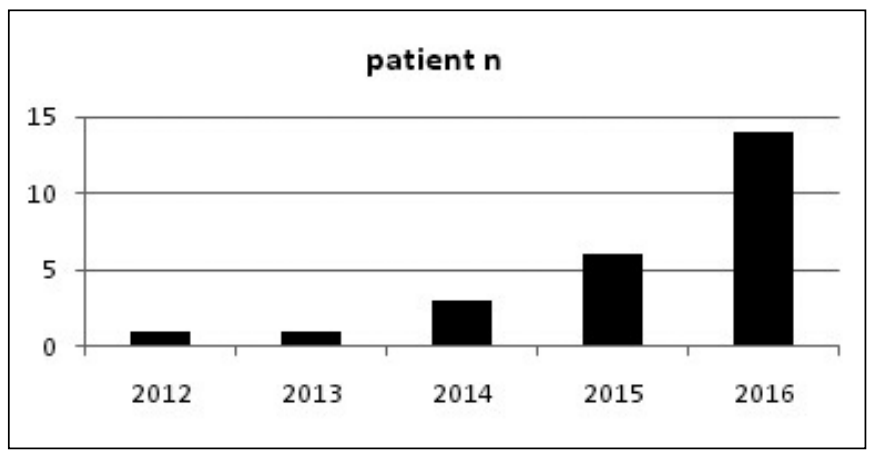

Figure 5: Number of patients who underwent laminar screws in the years of the study period.

The frequency of usage of laminar screws in our clinic was increased in time during the study period. We performed laminar screws in one case in each of first and second years, in 3 cases in the $3^{\text {rd }}$ year, in 6 cases in the $4^{\text {th }}$ year, and in 14 cases in the last year (Figure 5). Besides, while the levels were not suitable for other screw types in 19 screws out of 25 performed during the first 4 years of the study, this rate was 9 of 29 in the last year $(p=0.0009)$. The rate of screw malposition was not statistically different between these two periods $(3 / 25$ and $8 / 29$ respectively, $p=0.19$ ).

\section{DISCUSSION}

The laminar screw method was first described for $\mathrm{C} 2$ fixation as a salvage procedure in challenging cases with thin pedicles and small lateral masses to prevent vertebral artery injuries by Wright in 2004 (34). The laminar screw technique has some advantages such as little risk to the vertebral artery in the operation for $\mathrm{C} 2$ to $\mathrm{C} 6$ screws, technical simplicity and no absolute need for fluoroscopy during surgery (32). Use of the technique increased in time in cases not only with severe deformities and altered anatomy, but also in cases with normal anatomy (4), and it was used in not only C2 but in C7 and upper thoracic levels, and even in other subaxial levels as well.
It has been demonstrated that the technique provided comparable stability and fixation in terms of insertional torque, pullout strength, and resistance to flexion and extension, but there may be a little less resistance to lateral bending at the C2 level $(2,5,6,10,18)$. Ilgenfritz et al. found in a biomechanical cadaveric study that $\mathrm{C} 7$ laminar screws were as strong as C7 pedicle screws and significantly stronger than C2 laminar screws (14). Similarly in our study, it was found that the $\mathrm{C} 7$ screws were stronger and revision was required for C2 screws. McGirt et al. reported that upper thoracic laminar screws are almost as stable as pedicle screws to stabilize the cervicothoracic junction (22).

There have been varying reports in the literature regarding the minimum diameter of the lamina of $\mathrm{C} 2$ level needed to safely place laminar screws. Mandel et al. reported that at least $5 \mathrm{~mm}$ laminar diameter was required (21) while Pelton et al. proposed that a diameter of $4 \mathrm{~mm}$ is sufficient (26). Ma et al. reported in a study including 120 cadaveric specimen of the Asian population that $14.2 \%$ of specimens had laminae of insufficient size $(<4 \mathrm{~mm})$ for screw placement at least on one side (20), and $5 \%$ of the specimens had thinner laminae bilaterally. In the radiological study by Saetia and Phankhonksab (27), $79 \%$ of adults had C2 lamina with an inner transverse diameter larger than $3.5 \mathrm{~mm}$ allowing screw placement. Ilgenfritz et al. reported in a radiological study again that the majority of $\mathrm{C} 7$ laminae were suitable for the placement of bilateral laminar screws (14). Hu et al. reported that most T1 to T3 segments had adequate laminar height and width to place bilateral laminar screws in adults (12). Molina et al. found that $78 \%$ of upper thoracic laminae could accept a $4.0-\mathrm{mm}$ screw with $1.0 \mathrm{~mm}$ of clearance in a study on 52 children (24).

In our country, the posterior cervical screw-rod systems in the market have screws with 3.5 or $4 \mathrm{~mm}$ diameter, and we accepted as safe to perform screws in laminae $>4.5 \mathrm{~mm}$ in diameter. In our study, a unilateral screw was used (C2: 2, C5: 1, C6: 1, C7: 2) because of thinner laminae in the other side in only 6 segments. 
When the diameter of the lateral part of the lamina was thinner than $4.5 \mathrm{~mm}$ but the medial part was thicker, we preferred to use a shorter screw not reaching the thinnest part of that lamina instead of using a unilateral screw. It is mandatory to evaluate the preoperative CT scan carefully, to measure the size of the lamina and to estimate the length of the screw for ensuring adequate bone for the screw (9). However after a careful evaluation of radiologic anatomy, some modifications of the technique can be performed to strengthen the hardware with more penetration area in the bone.

Laminar screw fixation is increasingly used at the C2, C7 and upper thoracic levels. However, there were only a few case reports that presented their use at the subaxial levels other than C7. Alvin et al. (1), and Shin et al. (30) reported that acceptance of unilateral laminar screws at the C3-6 levels was quite lower than $\mathrm{C} 2$ or $\mathrm{C} 7$, and acceptance of bilateral screws was very low. Tanabe et al. reported 3 cases who underwent C3-6 laminar screws and one of them was a 15 year-old child (33). Chamoun et al. reported 7 children who underwent axial or subaxial laminar screws with bilateral C3 laminar screw in one patient (3). Hong et al. reported 11 adult patients but they used 1.6 or $2 \mathrm{~mm}$ mini-screws and mini-plate to fix the open laminae and it was therefore not a real stabilization procedure (11). We performed 4 C3 to C6 laminar screws in 2 patients. In a 6 year-old boy with a high degree of congenital craniocervical abnormalities, a unilateral screw at the $\mathrm{C} 5$ and bilateral screws at the C6 were placed, and in an adult female patient with cervical deformity due to infection, unilateral C6 laminar screw fixation was performed with a contralateral lateral mass screw because one lateral mass was fractured during surgery.

In the first patient in our series, we used a hybrid system with a pedicle screw in one side and a laminar screw in the other. Du et al. reported a series consisting of 11 cases treated with such a hybrid system for $\mathrm{C} 2$ fixation with a good bony union (8), as in our patient. Sairyo et al. introduced their strategy for safe screwing and its clinical results in a series consisting of 17 patients and 146 screws, and they recommended the use of C2 laminar screws when the $C 2$ pedicle is thinner than $3.5 \mathrm{~mm}$ (28). We performed laminar screws mostly in patients with an anatomical handicap to using other types of screws in the first few years of the study period. However, thereafter we used the technique as the first choice in most of our patients without any anatomical handicap because of the simplicity of the technique and the low risk rate.

It is very important for the laminar screw technique for the laminar height at midline to be at least twice the screw diameter as the two screws cross at the midline (35). In the series of Takayasu et al. (32), $83 \%$ of the patients had unilateral use and only $17 \%$ had bilateral use among the 24 patients who underwent C2 laminar screws. In our series, there were 2 cases with a laminar height less than $9 \mathrm{~mm}$ at midline. In both of these cases together with another one who underwent a C2 laminar screw procedure, the $\mathrm{C} 2$ spinous process was bifid almost entirely along its length, and a modification of the technique of screw insertion was required. In these cases, the screws were inserted from the medial sides of the bifid spinous processes instead of the lateral sides and shorter screws were used with a more vertical orientation. Kabir and Casey reported a similar technique to solve the problem of difficulty in bone graft placement due to the position of the head of C2 laminar screws, and they recommended insertion of the unilateral screw in that technique (16). However, in our modification in the cases with almost full bifid C2 spinous processes, the base of the spinous process was already wider and bilateral screws could be performed after removal of the two tips of the spinous process.

The most frequently seen complication of a laminar screw is medial cortical breach. Ma et al. reported a high rate of misplaced screws with 10 cortical breaches in their study of 68 translaminar screws (19). There is a risk of spinal cord injury in a ventral cortical breach (13). However most of these malpositions are asymptomatic and do not cause any serious consequences or weakness of the hardware. Parker et al. reported a lower rate of malposition for laminar screws than for pedicle screws at the C2 level (1.3\% translaminar breach versus $7 \%$ pedicle breach) (25). In our series, 11 out of 54 screws penetrated the ventral laminar cortices. There were no neurological deficits due to screw malposition. Only one of them was removed because it entered with full screw thickness into the spinal canal and caused laminar fracture.

Jea et al. described a new laminar screw technique to avoid ventral cortical breach (15). They recommended inserting the screw with an exit at the facet-laminar junction, allowing direct visualization of the tip of the screw. Tanabe et al. recommended controlling the spinal canal by a dissector following the removal of ligamentum flavum to reduce the risk of spinal canal penetration (33). Xia et al. also reported a modified technique to reduce this risk at the cervicothoracic junction (36). They made a tiny unicortical hole at the middle of the contralateral lamina enabling seeing directly the screw through that hole to prevent violating the spinal canal, and they reported good clinical results in 12 patients.

It was reported that the $\mathrm{C} 2$ laminar screw technique provided high fusion rates. Dorward et al. noted a $97.6 \%$ fusion rate in a series consisting of 41 patients who received C2 laminar screws (7). Singh and Cree reported 8 children aged between 2 to 17 years without any complication, and all patients maintained stable constructs on imaging studies at the last followup evaluation after 1 to 24 months (31). Savage et al. reported a series consisting 18 children younger than 5 years of age where $11(91.7 \%)$ of the 12 patients followed for 6 months or longer showed radiographic stability or completed fusion (29). In the series consisting of 27 adult patients by Meyer et al. (23), the fusion rate for patients with $\mathrm{C} 1 / \mathrm{C} 2$ fixation was $92.9 \%$. On the other hand, Parker et al. reported that the 1-year durability of $\mathrm{C} 2$ laminar screws might be inferior to C2 pedicle screws for subaxial (C2 to caudal) fusions, but equally effective for axial (C1-2 or C1-3) cervical fusions (25). In our series, the fusion rate was $75 \%$ in 16 patients whose radiological follow-up period was longer than 6 months. However, the unilateral C2 laminar screw was loosened in only one patient out of 4 cases in whom fusion did not develop (6.25\%). In other 3 patients without fusion, laminar screws were good but other screws were loosened or fully got out. 


\section{- CONCLUSION}

The laminar screw is a new method for posterior stabilization of C2, C7 and upper thoracic levels. In some specific cases in whom other screw techniques could not be performed because of anomalies or other pathologies, laminar screws could be used at subaxial levels other than $\mathrm{C} 7$ as well. The technique is quite easy, safe and effective with careful radiological evaluation before the operation. Some modifications may be required according to the anatomical differences of the laminae.

\section{REFERENCES}

1. Alvin MD, Abdullah KG, Steinmetz MP, Lubelski D, Nowacki AS, Benzel EC, Mroz TE: Translaminar screw fixation in the subaxial cervical spine: Quantitative laminar analysis and feasibility of unilateral and bilateral translaminar virtual screw placement. Spine (Phila Pa 1976) 37(12): E745-751, 2012

2. Benke MT, O'Brien JR, Turner AW, Yu WD: Biomechanical comparison of transpedicular versus intralaminar C2 fixation in C2-C6 subaxial constructs. Spine (Phila Pa 1976) 36(1): E33-37, 2011

3. Chamoun RB, Relya KM, Johnson KK, Whitehead WE, Curry DJ, Luerssen TG, Drake JM, Jea A: Use of axial and subaxial translaminar screw fixation in the management of upper cervical spinal instability in a series of 7 children. Neurosurgery 64(4):734-739, 2009

4. Cho W, Le JT, Shimer AL, Werner BC, Glaser JA, Shen FH: The insertion technique of translaminar screws in the thoracic spine: Computed tomography and cadaveric validation. Spine J 15(2):309-313, 2015

5. Claybrooks R, Kayanja M, Milks R, Benzel E: Atlantoaxial fusion: A biomechanical analysis of two C1-C2 fusion techniques. Spine J 7:682-688, 2007

6. Dmitriev AE, Lehman RA Jr, Helgeson MD, Sasso RC, Kuhns C, Riew DK: Acute and long-term stability of atlantoaxial fixation methods: A biomechanical comparison of pars, pedicle, and intralaminar fixation in an intact and odontoid fracture model. Spine 34:365-370, 2009

7. Dorward IG, Wright NM: Seven years of experience with C2 translaminar screw fixation: Clinical series and review of the literature. Neurosurgery 68:1491-1499, 2011

8. Du S, Ni B, Lu X, Guo X, Guo Q, Yang J, Chen F: Application of unilateral $\mathrm{C} 2$ translaminar screw in the treatment for atlantoaxial instability as an alternative or salvage of pedicle screw fixation. World Neurosurg 97:88-92, 2016

9. Ghori A, Le HV, Makanji $H$, Cha T: Posterior fixation techniques in the subaxial cervical spine. Cureus 7(10):e338, 2015

10. Gorek J, Acaroglu E, Berven S, Yousef A, Puttlitz CM: Constructs incorporating intralaminar C2 screws provide rigid stability for atlantoaxial fixation. Spine (Phila $\mathrm{Pa}$ 1976) 30:1513-1518, 2005

11. Hong JT, Sung JH, Son BC, Lee SW, Park CK: Significance of laminar screw fixation in the subaxial cervical spine. Spine (Phila Pa 1976) 33(16):1739-1743, 2008
12. Hu QF, Xu RM, Pan H, Zhou H, Lei W: Translaminar screw fixation in the upper thoracic spine: Computed tomographybased quantitative laminar analysis and feasibility study of translaminar virtual screw placement. Cell Biochem Biophys 73(1): 191-198, 2015

13. Hu Y, Yuan ZS, Spiker WR, Albert TJ, Dong WX, Xie H, Yuan JB, Wang CT: Deviation analysis of C2 translaminar screw placement assisted by a novel rapid prototyping drill template: A cadaveric study. Eur Spine J 22: 2770-2776, 2013

14. Ilgenfritz RM, Gandhi AA, Fredericks DC, Grosland NM, Smucker JD: Considerations for the use of C7 crossing laminar screws in subaxial and cervicothoracic instrumentation. Spine (Phila Pa 1976) 38(4):E199-204, 2013

15. Jea A, Sheth RN, Vanni S, Green BA, Levi AD: Modification of Wright's technique for placement of bilateral crossing C2 translaminar screws: Technical note. Spine J 8:656-660, 2008

16. Kabir SM, Casey AT: Modification of Wright's technique for C2 translaminar screw fixation: Technical note. Acta Neurochir (Wien) 151(11):1543-1547, 2009

17. Kretzer RM, Sciubba DM, Bagley CA, Wolinsky JP, Gokaslan ZL, Garonzik IM: Translaminar screw fixation in the upper thoracic spine. J Neurosurg Spine 5(6):527-533, 2006

18. Lapsiwala SB, Anderson PA, Oza A, ResnickDK: Biomechanical comparison of four $\mathrm{C} 1$ to $\mathrm{C} 2$ rigid fixative techniques: Anterior transarticular, posterior transarticular, $\mathrm{C} 1$ to $\mathrm{C} 2$ pedicle, and C1 to C2 intralaminar screws. Neurosurgery 58:516-521, 2006

19. Ma W, Feng L, Xu R, Liu X, Lee AH, Sun S, Zhao L, Hu Y, Liu G: Clinical application of $\mathrm{C} 2$ laminar screw technique. Eur Spine J 19:1312-1317, 2010

20. Ma XY, Yin QS, Wu ZH, Xia H, Riew KD, Liu JF: C2 anatomy and dimensions relative to translaminar screw placement in an Asian population. Spine 35:704-708, 2010

21. Mandel IM, Kambach BJ, Petersilge CA, Johnstone B, Yoo $\mathrm{JU}$ : Morphologic considerations of $\mathrm{C} 2$ isthmus dimensions for the placement of transarticular screws. Spine 25:1542-1547, 2000

22. McGirt MJ, Sutter EG, Xu R, Sciubba DM, Wolinsky JP, Witham TF, Gokaslan ZL, Bydon A: Biomechanical comparison of translaminar versus pedicle screws at T1 and T2 in long subaxial cervical constructs. Neurosurgery 65 Suppl 6:167172,2009

23. Meyer D, Meyer F, Kretschmer T, Börm W: Translaminar screws of the axis-an alternative technique for rigid screw fixation in upper cervical spine instability. Neurosurg Rev 35(2):255-261, 2012

24. Molina C, Scuibba DM, Chaput C, Tortolani PJ, Jallo GI, Kretzer RM: A computed tomography-based feasibility study of translaminar screw placement in the pediatric thoracic spine. J Neurosurg Pediatr 9(1):27-34, 2012

25. Parker SL, McGirt MJ, Garcés-Ambrossi GL, Mehta VA, Sciubba DM, Witham TF, Gokaslan ZL, Wolinsky JP: Translaminar versus pedicle screw fixation of C2: Comparison of surgical morbidity and accuracy of 313 consecutive screws. Neurosurgery 64(5 Suppl 2): 343-348, 2009

26. Pelton MA, Schwartz J, Singh K: Subaxial cervical and cervicothoracic fixation techniques-indications, techniques, and outcomes. Orthop Clin North Am 43:19-28, 2012 
27. Saetia K, Phankhonksab A: C2 anatomy for translaminar screw placement based on computerized tomographic measurements. Asian Spine J 9(2):205-209, 2015

28. Sairyo K, Sakai T, Higashino K, Tamura T, Katoh S, Yasui $\mathrm{N}$ : Cervical and upper thoracic screwing for spinal fusion: Strategy for its safe insertion to avoid major complications. Arch Orthop Trauma Surg 129(11):1447-52, 2009

29. Savage JG, Fulkerson DH, Sen AN, Thomas JG, Jea A: Fixation with C-2 laminar screws in occipitocervical or C1-2 constructs in children 5 years of age or younger: A series of 18 patients. J Neurosurg Pediatr 14(1):87-93, 2014

30. Shin SI, Yeom JS, Kim HJ, Chang BS, Lee CK, Riew KD: The feasibility of laminar screw placement in the subaxial spine: Analysis using 215 three-dimensional computed tomography scans and simulation software. Spine J 12(7):577-584, 2012

31. Singh B, Cree A: Laminar screw fixation of the axis in the pediatric population: A series of eight patients. Spine J 15(2): e17-25, 2015
32. Takayasu M, Aoyama M, Joko M, Takeuchi M: Surgical intervention for instability of the craniovertebral junction. Neurol Med Chir (Tokyo) 56:465-475, 2016

33. Tanabe $H$, Aota $Y$, Saito $T$ : Laminar screw fixation in the subaxial cervical spine: A report on three cases. World $\mathrm{J}$ Orthop 7(10):695-699, 2016

34. Wright NM: Posterior C2 fixation using bilateral, crossing C2 laminar screws: Case series and technical note. J Spinal Disord Tech 17(2):158-162, 2004

35. Xia DD, Lin SL, Chen W, Shen ZH, Li Y, Wang XY, Xu HZ, Chi YL: Computed tomography morphometric analysis of C2 translaminar screw fixation of Wright's technique and a modified technique in the pediatric cervical spine. Eur Spine $J$ 23:606-612, 2014

36. Xia DD, Yan MJ, Zhang JJ, Zhou F, Xu HM, Wang YL, Tan $J$, Wang $X Y$ : Modified translaminar screw fixation in the cervicothoracic junction (C7-T2): A technical note. Eur Spine J 25(6):1661-1664, 2016 